\title{
THE ROLE OF LEASING UNDER ADVERSE SELECTION
}

Igal Hendel

Alessandro Lizzeri

Working Paper 6577

http://www.nber.org/papers/w6577

\author{
NATIONAL BUREAU OF ECONOMIC RESEARCH \\ 1050 Massachusetts Avenue \\ Cambridge, MA 02138 \\ May 1998
}

We would like to thank Gene Grossman and Steve Tadelis as well as seminar audiences at University of California at Berkeley, Northwestern University, SUNY Stony Brook, Universita' di Venezia, University of Minnesota, and University of Wisconsin. Financial support for this project by NSF grant SBR-9711355 is gratefully acknowledged. Any opinions expressed are those of the authors and not those of the National Bureau of Economic Research.

(C) 1998 by Igal Hendel and Alessandro Lizzeri. All rights reserved. Short sections of text, not to exceed two paragraphs, may be quoted without explicit permission provided that full credit, including $(\mathbb{C}$ notice, is given to the source. 
The Role of Leasing under Adverse Selection

Igal Hendel and Alessandro Lizzeri

NBER Working Paper No. 6577

May 1998

JEL Nos. D82, L15

\begin{abstract}
Leasing contracts specify a rental rate and an option price at which the used good can be bought at the termination of the lease. This option price cannot be controlled when the car is sold. We show that in a world with symmetric information this additional control variable is useless; equilibrium allocations and profits to lessors are unaffected by the option prices. In contrast, under adverse selection, leasing contracts affect equilibrium allocations in a way that matches observed behavior in the car market.

We show that a social planner can use leasing contracts to improve welfare but they are imperfect tools; they cannot generally achieve first best while other mechanisms can. We also show that a producer with market power can benefit from leasing contracts for two reasons: better pricing of the option of keeping the used good, and market segmentation. Moreover, despite the fact that lessors could structure contracts to prevent adverse selection (by raising the option price so high that no lessee keeps the used good) we show that this is not in their interest; a keeping option will always be included in some contracts.
\end{abstract}

Igal Hendel

Department of Economics

Princeton University

Princeton, NJ 08544

and NBER

igal@princeton.edu
Alessandro Lizzeri

Department of Economics

Princeton University

Princeton, NJ 08544

lizzeri@princeton.edu 


\section{Introduction}

Leasing contracts are extensively used in durable goods markets. A third of the capital equipment in US corporations is leased. In the automobile market the importance of leases has been growing and has reached the point where in 1996, one out of three new cars had been leased. If one consumer leases and another buys, should we expect them to behave differently in secondary markets or are the two consumers simply financing a similar utilization of a durable good in a different way?

Evidence in the car market, shows that buyers and lessees behave in a different manner. First, the turnover of leased cars is higher than that of sold cars. Second, off-lease used cars seem to be of better quality than pre-owned cars of the same vintage. Evidence of the first phenomenon is particularly strong. Lessees buy their cars at maturity only $25 \%$ of the time. Since most car leases have a two to three year duration, this means that a large fraction of leased cars are sold in the used market by the time they are three years old. ${ }^{1}$ In $199642 \%$ of the so called premium used cars, which include two to four year old cars, were off-lease cars. But back in 1993 only one out of four new cars was leased. For leased cars to account for $42 \%$ of trades in 1996 , while only being $25 \%$ of the stock in 1993 , they must have a propensity to be traded within the first four years which is $117 \%$ larger than that of sold cars. Further evidence is provided by Sattler (1995) who reports that $56 \%$ of 1989 car models in his sample were held by their first owner five years later. Moreover, the average length of period that all new cars (leased and bought) are held before changing hands is almost 6 years. This means that new car buyers hold on to their cars much longer than consumers who lease.

Evidence that off-lease cars are better quality is a little weaker but still suggestive. In the automotive press it is a common finding. For instance, "[T]he industry-wide assumption [is] that the most desirable used vehicle is the consumer off-lease variety...." Moreover, advertisements of used cars for sale often specify whether a car is off-lease. This would hardly be highlighted if the perception was that off-lease cars are no better than sold cars. Finally,

\footnotetext{
${ }^{1}$ Polk's analysis estimates 2.88 million off-lease vehicles returned to the used car market in 1997, 87 percent being two- and three-year-old vehicles. In fact, final 1997 numbers should show off-lease vehicles representing 65 percent of two-year-old vehicles on the market, and 57 percent of three-year-old vehicles. Source, Polk Corporation: http://www.polk.com/whatsnews/jan98/01139801.html

${ }^{2}$ Polk Corp, Press release 1996.
} 
Desai and Purohit (1997), using auction data for a popular car model, find that off-lease cars sell at a premium or, more precisely, that the price decline is slower than for sold cars.

How can we explain these phenomena? Can manufacturers benefit from appropriately designing leasing contracts? What are the consequences for social welfare? We present a model to address these questions.

A leasing contract, beyond specifying the rental payments for the good, also specifies the option price at which the used good can be bought at maturity. This option price can be set independently of the price in the used market and provides an additional control variable for the manufacturer of the good. If the option price is set above the market clearing price in the used market, lessees choose which cars to keep on the basis of the option price. We show that in the absence of asymmetric information the additional control variable is useless; market allocations and profits for manufacturers are the same for any menu of leasing contracts. We then introduce the possibility of adverse selection in the used market. We build on the model of adverse selection in durable goods markets presented in Hendel and Lizzeri (1997b). The key ingredients of the model are the following. Consumers are long lived and have heterogeneous valuation for quality. Cars are produced every period and they depreciate. Thus, high valuation consumers favor new cars and low valuation consumers favor used cars. This generates the possibility of exchange in the second hand market.

When there is adverse selection, then leasing affects equilibrium allocations in the market. We show that when leasing and selling contracts are offered simultaneously on the market, then consumers who lease are higher valuation consumers. Thus, offering both contracts serves to segment the market. Moreover, the percentage of off-lease cars that are returned at maturity is higher than the percentage of pre-owned cars that are traded and the off-lease cars have higher average quality. These predictions of the model match the empirically observed differences in behavior between lessees and buyers.

We then investigate the welfare effects of leasing contracts. We show that a social planner can use leasing contracts to ameliorate the welfare distortion caused by adverse selection. ${ }^{3}$ However, except for the case where there are only two types of consumers, no menu of leasing contracts can achieve even the second best allocation. Leasing contracts are good tools to

\footnotetext{
${ }^{3}$ This point is related to the analysis in Guha and Waldman (1997) which is discussed in more detail later.
} 
control the keeping behavior of new car consumers and therefore to adjust the volume of trade in the used car market. However, they cannot deal well with the distortion in the allocation of used goods among used good buyers. Solving this distortion requires that finer information about the quality of the used goods be obtained from the first users. A menu of leasing contracts is not capable of doing this. We show that there exists a mechanism that completely solves the adverse selection problem; the first best allocation can be achieved by an incentive compatible, individually rational, and budget balanced mechanism.

We then consider the issue of the optimal choice of leasing contracts by a monopolist. We present an example that has the striking feature that the manufacturer can raise the option price above the market clearing price in the used market and increase its profits without affecting the equilibrium allocation in the market. The reason the monopolist profits from increasing the option price is the following: Under selling the option of keeping is implicitly priced by the market clearing price in the used market. With adverse selection, this price reflects the fact that the traded used good is of lower quality than the good that is kept by the new car buyer. Thus, the new car buyer gets to keep a high quality good that is priced as if it were a low quality one. Leasing allows the manufacturer to raise the option price thereby reducing the competitive threat that the used good poses to the new good. ${ }^{4}$ We go on to show that this allows the manufacturer to profitably expand output and that manufacturers with unreliable cars benefit more from leasing.

Given the ability to control behavior in the used market, and given the fact that adverse selection is commonly perceived to have negative effects on market allocations, it is natural to ask why leasing contracts often include the option of buying the good at the end of the lease. If this option were very expensive, all used goods would be returned resulting in a pool of used cars that does not suffer from adverse selection. We show that allowing some lessees the option of keeping the used good is the optimal policy for the manufacturer despite the

\footnotetext{
${ }^{4}$ Our analysis is thus in contrast with McConnel and Schallheim (1983) who argue that "In many cases leases grant the lessee an option to purchase the leased asset at its 'fair market value' at the maturity date of the contract. However, the lessee can purchase the asset at its market price at maturity of the lease whether or not the contract contains such an option. Thus, an option to purchase the asset at its fair market price is valueless and the equilibrium rental payments will be the same whether or not the lease contract contains such an option." The contrast is due to the fact that we study a world with asymmetric information.
} 
fact that lessees who have private information about the quality of the good will only return the worse quality cars. This is due to the following phenomenon: If no keeping option is allowed, all used car consumers purchase cars with the same average quality. But some of these consumers have valuations for quality that are almost as high as those of the lowest valuation consumers who consume new goods, whereas other used car consumers have much lower valuations. Thus a menu of leasing contracts, where one of the contracts includes an option for keeping allows for a better segmentation of the market.

\section{$2 \quad$ Related Literature}

Several roles for leasing have been suggested in the durable goods literature. Bulow (1986) shows that leasing can be used by a monopolist to overcome the Coasian time inconsistency problem. Waldman (1996) and Hendel and Lizzeri (1997a) show that manufacturers may choose to lease because this gives them additional market power in the used market. The monopolist exercises this power by scrapping some of the used units. These papers provide rationales for leasing but do not contain analyses of adverse selection and have no predictions on how units that were sold and units that were leased differ in the secondary market.

There is a large literature in finance that focuses on the valuation of leasing contracts. Most of this literature takes as given the structure of the leasing contract and obtains the equilibrium lease value and the rental rate for a wide variety of leasing contracts. ${ }^{5}$ There is also a literature that addresses the tax incentives for leasing. Tax issues cannot fully explain the effects of leasing in the car market because, while the tax advantages of leasing were lowered in the tax reform act of 1986, the importance of leasing has increased. ${ }^{6}$

Smith and Wakeham (1985) provide the most extensive analysis of the determinants of corporate leasing policy. Their analysis is informal but very insightful. Some of the issues that they consider are the following: Repossessing an asset is easier for a lessor than for a secured debtholder in the event of bankruptcy. Thus, firms that have problems obtaining financing might be expected to lease. Sharpe and Nguyen (1995) present evidence that firms likely to face high financial contracting costs lease a higher proportion of their capital equipment. This

\footnotetext{
${ }^{5}$ Examples are papers by Grenadier (1995, 1996) and McConnel and Schallheim (1983).

${ }^{6}$ See Sharpe and Nguyen (1995) for a discussion of this.
} 
is an implausible explanation for the car market because it is unlikely that it can account for the observed higher turnover of leased cars as opposed to sold cars. ${ }^{7}$ Smith and Wakeham also argue that leasing might be favored if the lessees plan to use the equipment for less than its useful life and the lessor has a comparative advantage in disposing of the asset. However, they acknowledge that this transaction cost explanation for leasing is problematic since it requires that the comparative advantage of the manufacturer not be available under selling. Many manufacturers (including car manufacturers) however, allow dealers to accept trade-ins thereby making available to buyers the same advantage that is available to lessees. Smith and Wakeham also discuss the rationales for a number of common provisions in leasing contracts. The most relevant to our analysis is their discussion of options to purchase at the end of the lease. They argue that this provision serves to give an incentive to the user to take care of the asset. We show that there is also a market segmentation reason for the existence of such provisions.

Guha and Waldman (1996) is the only other paper that deals with leasing and adverse selection. The basic environment they model is quite similar to ours. The focus of their paper is to show that "leasing solves the lemons problem;" leasing contracts offered by a competitive industry would lead to efficient allocations. Most of their analysis is concerned with an environment where there are two types (qualities) of used cars and two types (valuations for quality) of consumers. Under additional assumptions, in this world the social optimum and the equilibrium outcome in a competitive industry are the same and they involve the absence of a keeping option in the leasing contract; all users return the car at the end of the lease. They recognize that this is a special case and discuss an example with three types of cars where the social optimum and the equilibrium outcome in a competitive industry still coincide but they both allow lessees to keep the highest realization of quality of the used good.

As mentioned above, we show that leasing contracts can achieve a first best allocation only in the case where there is a single type of used car consumer. When there are many types of used car consumers there is a misallocation of quality in the secondary market

\footnotetext{
${ }^{7}$ Because of the higher turnover, consumers who lease spend more money on average than consumers who buy. Thus, it is unlikely that lessees are those who have higher financial contracting costs.
} 
which cannot be resolved through leasing contracts. We show that there exists an incentive compatible, individually rational and balanced budget mechanism that implements the first best allocation. Thus, in general, leasing contracts cannot even achieve the incentive efficient allocation.

Other differences with Guha and Waldman are the following: Our analysis shows how firms with market power can benefit from the appropriate design of leasing contracts. We show that selling and leasing contracts can both be offered simultaneously in equilibrium, and how this mixture generates outcomes that match observed patterns in the car market. In our paper the mix arises solely out of market segmentation in the presence of adverse selection. Guha and Waldman show that a mix of selling and leasing can arise in a world where in addition to adverse selection there is moral hazard on maintenance and some consumers have lower costs of maintenance. We will highlight the differences with their analysis at several points in the paper.

Laffont and Tirole (1996) study the problem of inducing the right amount of pollution and investment in pollution abatement. Despite the difference in the topic, their model has some similarity with the one that we study. They look at a two period problem where the second period private information is correlated with the first period private information and there is an investment in the first period. They show that the optimal mechanism involves an offer of two menus of option contracts depending on whether the agent decides to invest. In their model the allocation of pollution is not ex post efficient, while in our model the allocation in the optimal incentive compatible mechanism is ex post efficient. The main difference between the models is the existence of a second hand market, that is a crucial aspect of our model. This difference turns out to be important. 


\section{The Model}

We assume that there is an infinite horizon. Time is discrete, and there is a unit mass of consumers who live forever (no new consumers are born). Preferences resemble those in Mussa and Rosen (1978). In any given period each consumer demands at most one unit of the good, a consumer of type $\theta$ consuming a sequence of units with qualities $\left(q_{0}, q_{1}, \ldots\right)$ at prices $\left(p_{0}, p_{1}, \ldots\right)$ obtains utility $u(\theta, q, p)=\Sigma_{t=0}^{\infty} \delta^{t}\left(\theta q_{t}-p_{t}\right) \chi_{t}$ where $\chi_{t}$ is either zero or one depending on whether he consumes in period $t$ or not. We assume that consumers are heterogeneous and we represent the distribution of consumer tastes by the cumulative distribution function $F:[\underline{\theta}, \bar{\theta}] \rightarrow[0,1]$. With the exception of the example in section 7 and some of the discussion in section 6 , we assume that $F(\cdot)$ is strictly increasing and continuous. Consumer heterogeneity is essential for the used markets to have an allocative role (no trade would be possible if consumers were homogeneous). The value of $\theta$ is assumed to be unobservable so that trading is anonymous.

Goods last two periods. We denote by $v$ the quality of a new good and by $w$ the quality of a used one. Both $v$ and $w$ are assumed to be random variables. However, since the realization of $v$ will be irrelevant, we shall simply denote by $v$ the expectation of the quality of the new product. Let $G(\cdot)$ be the distribution of $w$ with support $\left[w_{l}, w_{h}\right]$. We assume that $G$ is strictly increasing and $w_{h} \leq v$ (the good depreciates).

Definition 1 We denote by $\theta_{z}$ the type such that $1-F\left(\theta_{z}\right) \equiv z$.

Thus, $\theta_{z}$ is the type such that there is a mass $z$ of consumers with higher valuation; for example, $\theta_{1 / 2}$ is the median type.

Goods can be sold or leased. Only new goods are leased and the length of a lease is one period. There are potentially many leasing contracts. Each contract $i$ is characterized by the rental price $P_{i}^{L}$ and the price of keeping the good at the end of the lease (or option price) $P_{i}^{k}$. The price at which a new good is sold is denoted by $P^{n}$. A special case of a leasing contract is in fact the selling contract. If the price of the option of keeping is set at zero $\left(P^{k}=0\right)$, the rental price $P^{L}$ is in fact a selling price. All cars that are returned at the end of the lease are then sold on the used market. ${ }^{8}$ Because of the presence of asymmetric information, the

\footnotetext{
${ }^{8}$ Waldman (1997) and Hendel and Lizzeri (1997a) show that a monopoly manufacturer may have an incen-
} 
used cars that are returned by consumers who chose different contracts are different goods. The price of a used good that was leased under contract $i$ is denoted by $P_{i}^{u}$. We assume that the type of contract is observable by used good buyers, i.e. the latter know whether they are buying a good that was leased under contract $i$ or contract $j$.

A customer who consumes a new good at date $t$ knows the realization of $w$ at date $t+1$ for that unit of the good. A buyer who decides to buy a used good does not know the value of $w$ for that good. We assume that there is an infinite number of consumers of each type so the realized distribution of qualities $w$ is $G(\cdot) .^{9}$

We shall denote by $y$ the output of new goods. We shall only analyze steady state equilibria. The mass of consumers who get to consume either a new or a used product at any date is at most $2 y$. We will first fix the menu of leasing contracts and/or $y$ to determine equilibrium behavior in the market. We then discuss the incentives for a manufacturer and a social planner to optimally choose output and the structure of contracts.

\section{Remarks}

We analyze the case of many possible leasing contracts for two reasons. First, we want to capture the differences observed in the car market between the behavior of lessees and the behavior of buyers. In the buying/leasing case we believe it is realistic to assume that used car consumers can distinguish between the pre-owned and off-lease units. As discussed in the introduction the automotive press does highlight the differences between off-lease cars and pre-owned cars. Moreover, used car buyers can easily distinguish between the two types of used cars by checking the title of the car. The second reason to be interested in the case of many contracts is to explore the welfare effects of adverse selection and the role of leasing contracts in ameliorating the distortions. We want to find out what allocations can be implemented through leasing contracts thereby discovering their limitations. For much of the analysis the reader can, with no loss, think of the case where there are only two contracts: leasing and selling. The analysis of the examples only focuses on these contracts.

To focus on the effects of asymmetric information we ignore the time consistency problem faced by manufacturers of durable goods. This would introduce an additional dimension tive to scrap some of the used units. We ignore this incentive to focus on the issues at hand.

${ }^{9}$ This is like a joint distribution of $\theta$ and another variable distributed independently of $\theta$, that plays no role in the model, it just captures that there is a density of each specific type $\theta$. 
in the differences between selling and leasing which would obscure the force that we want to highlight. Thus, when we discuss manufacturers' incentives we shall assume that they have the ability to commit. When goods depreciate, the commitment outcome can be an equilibrium of the game where a monopolist cannot commit. ${ }^{10}$

We neglect the issue of moral hazard on the part of consumers. This is a potentially important phenomenon since the level of maintenance that is chosen by new car consumers may depend on the terms of the leasing contract. A lessee who is facing a high option price and therefore anticipates not exercising the option to buy at the end of the lease might take less good care of the car. We justify this neglect on three grounds. First, most cars are still under warranty by the time the lease expires. This reduces the disincentive to maintain. Second, as mentioned in the introduction, the common perception is that cars coming off leases are better quality cars. This is consistent with our analysis and suggests that, if there is a moral hazard problem on the part of consumers, this problem is of secondary importance relative to the forces that we discuss. ${ }^{11}$ The third reason we neglect moral hazard is that interesting phenomena arise even in a world with pure adverse selection; including maintenance decisions by the consumer would add unnecessary complexity to our analysis. ${ }^{12}$

Results in sections 4 and 5 describe equilibrium allocations in the market for used goods given some prices in the new good market. The characterization does not rely on any assumption on the market structure of the producers of the good. We do not deal with optimal behavior of the manufacturer until section 7 where we present a simple monopolist example and section 8 where we describe some features of the optimal menu of contracts under both monopoly and competition.

\footnotetext{
${ }^{10}$ See Bond and Samuelson (1987).

${ }^{11}$ Some readers may have an objection in the opposite direction; leasing could be a way to overcome the moral hazard problem. Manufacturers are in a better position to verify the quality of the car at the end of a lease. However, if this were true, it is not clear why manufacturer could not do this for sold cars that are traded in at dealers. In fact, some manufacturers do certify some "pre-owned cars."

${ }^{12}$ Guha and Waldman (1997) contains a discussion of the issue of moral hazard under leasing.
} 


\section{An Irrelevance Result}

Before discussing adverse selection, we consider the case where there is no asymmetric information. This benchmark will allow us to better evaluate the impact of adverse selection on the optimal structure of leasing contracts. We show that in the absence of asymmetric information leasing contracts have no effects, the ability to manipulate the keeping price has neither an effect on profits nor on the equilibrium allocation.

Since the quality of the used cars is observable an allocation in the used market must specify which type consumes which quality. We must therefore define a function $\vartheta:\left[w_{l}, w_{h}\right] \rightarrow$ $[\underline{\theta}, \bar{\theta}]$ that specifies that a consumer of type $\vartheta(w)$ consumes a used good of quality $w$. Denote prices in the used market by a function $P^{u}:\left[w_{l}, w_{h}\right] \rightarrow \Re_{+}$that describes the price of every quality of used good. Used markets must clear for every quality $w$.

Let us briefly describe the equilibrium under a selling contract. ${ }^{13}$ In equilibrium, types in $\left[\underline{\theta}, \theta_{2 y}\right]$ do not buy cars at all, types in $\left[\theta_{2 y}, \theta_{y}\right]$ buy used cars, with lower types consuming lower qualities, and types in $\left[\theta_{y}, \bar{\theta}\right]$ buy new cars at every date. Thus there is a hundred percent volume of trade in the used market (all used units change hands); a new good buyer at date $t$ will be a new good buyer at all dates and therefore never holds on to a used good. In order to see why this is the case, consider a consumer who bought a new car at time $t$ and is an owner of a used car when used markets open at date $t+1$. Keeping the used car at date $t+1$ (thus postponing the purchase of a new car) is the same as buying a used car at time $t$ (keeping the used car has the same opportunity cost as buying one). Since the consumer preferred buying a new car at date $t$, he must prefer to sell the used car at date $t+1$ in order to buy a new car again. To obtain market clearing in the used market for every quality given that the supply of used cars is $y$ and the distribution of used car qualities is $G$, the function $\vartheta(\cdot)$ must be increasing (higher types consume higher quality) and must satisfy $F(\vartheta(w))-F\left(\theta_{2 y}\right)=y G(w) \forall w \in\left[w_{l}, w_{h}\right]$ (market clearing for every quality $w$ ).

Equilibrium prices under selling can be shown to be the following:

$$
P^{u}(w)=\int_{w_{l}}^{w} \vartheta(s) d s+\theta_{2 y} w_{l}
$$

\footnotetext{
${ }^{13}$ For details see Hendel and Lizzeri (1997b) Section 3.2.
} 


$$
P^{n}=\theta_{y}\left(v-w_{h}\right)+P^{u}\left(w_{h}\right)+\delta \int_{w_{l}}^{w_{h}} P^{u}(w) d G(w)
$$

The expression for $P^{u}(w)$ is obtained through incentive conditions for used car consumers. The expression for $P^{n}$ can be interpreted by observing that

$$
P^{n}-P^{u}\left(w_{h}\right)=\theta_{y}\left(v-w^{h}\right)+\delta E\left(P^{u}(w)\right)
$$

Thus, the extra cost of buying a new car relative to the best available substitute (the highest quality used car) is equal to the extra quality of the new car $\left(v-w^{h}\right)$, evaluated by the marginal consumer of the new car $\theta_{y}$, plus the expected discounted resale value of the used $\operatorname{car} \delta E\left(P^{u}(w)\right)$.

Denote now by $\hat{P}^{L}$ the implied rental price of a new car in a selling-only regime. By equation $2 \hat{P}^{L}$ must satisfy:

$$
\hat{P}^{L}=\theta_{y}\left(v-w_{h}\right)+P^{u}\left(w_{h}\right)
$$

Under a leasing contract the manufacturer specifies a rental price $P^{L}$, and a function $P^{k}:\left[w_{l}, w_{h}\right] \rightarrow \Re_{+}$which determines the future price of keeping a car of quality $w$. Notice first that if the manufacturer sets $P^{k}(w)=P^{u}(w)$ then the equilibrium is the same as under selling and the equilibrium $P^{L}$ is $\hat{P}^{L}$. The question we want to ask now is the following: can the manufacturer profit from manipulating $P^{k}(w)$ ? The answer is given in the following proposition. Not only does the manufacturer not gain, but nothing is affected by manipulating $P^{k}(\cdot)$, except that any gaps between $P^{k}(w)$ and $P^{u}(w)$ get capitalized into $P^{L}$.

Proposition 1 (i) Leasing has no effect on profits and on the equilibrium allocation.

(ii) The equilibrium $P^{u}(\cdot)$ satisfies equation 1 regardless of $P^{k}(\cdot) . P^{L}$ satisfies the following equation.

$$
P^{L}=\hat{P}^{L}+\delta \int_{w_{l}}^{w_{h}} \max \left\{P^{u}(w)-P^{k}(w), 0\right\} d G(w)
$$

Where $\hat{P}^{L}$ is given in equation 3 and $P^{u}(w)$ is given in equation 1

Proof: We shall show that for any $P^{k}(\cdot)$ the equilibrium allocation under selling is still an equilibrium under leasing, that $P^{L}$ satisfies 4 and that profits to a manufacturer are the same. We will omit the proof that the equilibrium is unique. 
Equation 4 says that the rental price of the new good has to be adjusted upward from $\hat{P}^{L}$ to capitalize all the gains that lessees can make in the used market by keeping the car and immediately selling in the used market when $P^{k}<P^{u}$. Thus, keeping decisions are unaffected by changing $P^{k}(\cdot)$ : when $P^{k}(w)<P^{u}(w)$ the true cost of keeping is $P^{u}(w)$ and the effective rental price of consuming a used cars is unchanged; when $P^{k}(w)>P^{u}(w)$ consumers who did not plan to keep at $P^{u}$ also do not keep at $P^{k}$, hence nobody pays a $P^{k}(w)>P^{u}(w)$. It is also clear that, given that the supply of used cars is unchanged, the equilibrium $P^{u}(\cdot)$ is unchanged and still satisfies equation 1. Thus, the equilibrium allocation is unchanged.

To obtain profits, from the previous analysis we get that in the used market the lessor sells cars of quality $w$ at $P^{u}(w)$ when $P^{u}(w)<P^{k}(w)$ and at $P^{k}(w)$ when $P^{u}(w)>P^{k}(w)$. We thus obtain that profits for a lessor who produces $y$ units and leases these units are:

$$
\Pi=\frac{y}{1-\delta}\left(P^{L}+\delta\left(\int_{\left\{w: P^{u}(w) \leq P^{k}(w)\right\}} P^{u}(w) d G(w)+\int_{\left\{w: P^{u}(w)>P^{k}(w)\right\}} P^{k}(w) d G(w)\right)\right)
$$

Substituting into this expression $P^{L}$ from equation 4 we obtain that profits are not affected by the structure of the leasing contract.

The proposition shows that the ability of the manufacturer to manipulate the option price has no role in a world with symmetric information. The intuition for this is that under observable quality consumers will find a way to exploit all the gains from trade and they will undo through trading any change in $P^{k}$.

An important feature of the equilibrium allocation in the case of no asymmetric information is that it is first best efficient, all types of consumers are matched with the right quality of the good. Moreover, it is easy to see that a competitive industry that produces the good at a marginal cost of $c$ would produce the optimal quantity of the good. This is important in reference to our welfare results in section 6 .

We could allow for a whole menu of functions $P_{i}^{k}(\cdot)$. However, since quality is observable, we can focus without loss of generality on a single function. This is because, in a world with observable quality, all consumers of new cars will consume new every period. Since they all consume the same bundle they will all choose the cheapest way to consume it. 


\section{Adverse Selection}

\subsection{Consumer Behavior}

We now turn to an analysis of the effects of leasing under adverse selection.

Let $w_{i}^{u}$ denote consumers' beliefs about the average quality of used cars that were leased under contract $i$ and were returned at the end of the lease. Clearly, rational consumers will always believe that $w_{i}^{u} \leq E(w)$, i.e. they will never believe that lessees keep the bad quality cars and return the good quality cars; at best they return all cars regardless of quality, in which case, $w_{i}^{u}=E(w)$. Because of adverse selection, unless $P_{i}^{k}$ is very high, typically we will have that $w_{i}^{u}<E(w)$. The average supplied quality, which we shall denote by $w_{i}^{A}$, is determined by the keeping behavior of the lessees who chose contract $i$. Of course, equilibrium requires $w_{i}^{u}=w_{i}^{A} \forall i$, i.e. in equilibrium expectations are correct. The appendix discusses the determination of $w_{i}^{A}$.

Consumers take as given the following variables: $\left\{w_{i}^{u}, P_{i}^{L}, P_{i}^{k}, P_{i}^{u}\right\}_{i \in I}$.

Define $V_{i}^{u}(\theta)$ to be the discounted utility of a consumer of type $\theta$ who buys a used car from leasing contract $i$ every period. ${ }^{14}$ Then,

$$
V_{i}^{u}(\theta)=\frac{\theta w_{i}^{u}-P_{i}^{u}}{1-\delta}
$$

The determination of the utility of consumers who contemplate leasing is more complex since such consumers must decide what to do when the lease period is over. They can exercise the option of keeping the used car by paying $P_{i}^{k}$ or return the car at no cost and lease another new car. These decisions clearly depend on the private information of the consumer, namely the quality of the car $w$ and the intensity of valuation for quality $\theta$. It is easy to show that optimal behavior is characterized by a cut-off rule; if the quality of the car is lower than some level $x_{i}(\theta)$, a consumer of type $\theta$ will return the car, if the car is of higher quality the consumer will exercise the option.

Assume a consumer of type $\theta$ chooses contract $i$ and behaves optimally conditional on this choice. We denote by $V_{i}^{L}(\theta)$ the discounted utility for a consumer who has no car, chooses to

\footnotetext{
${ }^{14}$ In what follows we shall suppress $P^{L}, P^{u}, P^{k}$ and $w^{u}$ as arguments of the value functions $V(\cdot)$ and cut-off functions $x(\cdot)$.
} 
lease a new car, decides for contract $i$ and then behaves optimally conditional on this choice.

$$
V_{i}^{L}(\theta)=\theta v-P_{i}^{L}+\delta\left[G\left(x_{i}(\theta)\right) V_{i}^{L}(\theta)+\left(1-G\left(x_{i}(\theta)\right)\right)\left(\theta E\left(w \mid w \geq x_{i}(\theta)\right)-P_{i}^{k}+\delta V_{i}^{L}(\theta)\right)\right]
$$

This expression has a simple interpretation. The first term $\left(\theta v-P_{i}^{L}\right)$ is the flow of utility enjoyed during the lease period. In the next period there are two possible events: either (1) the quality of the car turns out to be below the cut-off (with probability $G\left(x_{i}(\theta)\right)$ ) and the consumer starts a new lease, in which event he gets utility $V_{i}^{L}(\theta)$, or (2) the quality is higher than the cut-off (with probability $1-G\left(x_{i}(\theta)\right)$ ), in which event he enjoys a flow of utility of $\theta E\left(w \mid w \geq x_{i}(\theta)\right)-P_{i}^{k}$, and in the next period he starts a new lease which will then yield a utility of $V_{i}^{L}(\theta)$.

To determine the value of $x_{i}(\theta)$, observe that the consumer must be indifferent between (1) keeping the used good of quality $x_{i}(\theta)$ at a cost of $P^{k}$, and (2) initiating a new lease right away. Option (1) yields a utility of $\theta x_{i}(\theta)-P_{i}^{k}+\delta V_{i}^{L}(\theta)$. Option (2) yields a utility of $V_{i}^{L}(\theta)$. Therefore we have:

$$
\theta x_{i}(\theta)-P_{i}^{k}=(1-\delta) V_{i}^{L}(\theta)
$$

Proposition 2 Given the choice of contract $i$, optimal behavior for consumers who lease is characterized by a continuous increasing function $x_{i}:\left[\theta_{l}, \theta_{h}\right] \rightarrow\left[w_{l}, w_{h}\right]$ such that a consumer of type $\theta$ keeps all used cars of quality above $x_{i}(\theta)$ and returns all those with quality below $x_{i}(\theta)$, where $x_{i}(\theta)$ is given by equation 6 .

Moreover,

$$
V_{i}^{L}(\theta)=\frac{\theta v+\delta\left(1-G\left(x_{i}(\theta)\right)\right)\left(\theta E\left(w \mid w \geq x_{i}(\theta)\right)-P_{i}^{k}\right)-P_{i}^{L}}{1-\delta G\left(x_{i}(\theta)\right)-\delta^{2}\left(1-G\left(x_{i}(\theta)\right)\right)}
$$

We omit the proof of this proposition since it can be obtained by a simple modification of the arguments in Hendel and Lizzeri (1997b), Proposition 3.

Because the cut-off function is increasing higher types are less likely to exercise the option of keeping.

If cars are sold instead of leased, equation 7 must be modified to take into account the fact that when the consumer buys the car, he does not pay anything if he decides to keep and he gets $P^{u}$ if he decides to sell. This yields:

$$
V^{n}(\theta)=\frac{\theta\left[(v+\delta(1-G(x(\theta))) E(w \mid w \geq x(\theta))]+\delta G(x(\theta)) P^{u}-P^{n}\right.}{1-\delta G(x(\theta))-\delta^{2}(1-G(x(\theta)))}
$$


We now want to determine how optimal behavior partitions the set of consumers as either (1) non-buyers, (2) buyers of used cars of type $i$, or (3) lessees of contract $i$. The next proposition describes this classification. All of the statements in the proposition are consequences of the following standard self selection result.

Lemma 3 Suppose that consumers $\theta, \theta^{\prime}$ choose qualities $q$ and $q^{\prime}$ with $q>q^{\prime}$. Then $\theta>\theta^{\prime}$.

Proof: Denote the price of consuming quality $q$ by $P$ and the price of consuming quality $q^{\prime}$ by $P^{\prime}$. Then, $P>P^{\prime}$ since otherwise both types would choose quality $q$. Because type $\theta$ chooses quality $q, \theta q-P \geq \theta q^{\prime}-P^{\prime}$. Analogously, $\theta^{\prime} q^{\prime}-P^{\prime} \geq \theta^{\prime} q-P$. Combining the two inequalities we obtain $\theta^{\prime}\left(q-q^{\prime}\right) \leq P-P^{\prime} \leq \theta\left(q-q^{\prime}\right)$. Thus, since $P-P^{\prime}>0, \theta>\theta^{\prime}$.

$>$ From now on we shall restrict attention to the case where $P_{i}^{k} \geq P_{i}^{u}$. This is without loss of generality since, whenever $P_{i}^{u}>P_{i}^{k}$, all lessees will exercise the option regardless of the realization of quality because there is an arbitrage opportunity. Their keeping behavior $x_{i}(\theta)$ would thus be determined by $P_{i}^{u}$. Denote by $\Theta_{i}^{u}$ the set of types who consume used cars of type $i, \Theta_{i}^{n}$ the set of types who choose to lease a new car according to contract $i$.

Proposition 4 (i) Suppose that $w_{i}^{u}>w_{j}^{u}$. Then, if $\theta \in \Theta_{i}^{u}$ and $\theta^{\prime} \in \Theta_{j}^{u}, \theta>\theta^{\prime}$.

(ii) Suppose that $P_{i}^{k}>P_{j}^{k}$. Then, if $\theta \in \Theta_{i}^{n}$ and $\theta^{\prime} \in \Theta_{j}^{n}, \theta>\theta^{\prime}$.

(iii) If $\theta \in \Theta_{i}^{n}$ and $\theta^{\prime} \in \Theta_{j}^{u}, \theta>\theta^{\prime}$.

Proof: See Appendix.

Remarks: Proposition 4 says that the set of types is partitioned into two classes of non overlapping intervals. In the first class are consumers with relatively low valuations. These consumers buy used cars, with the lowest types buying used cars of low expected quality, and higher types buying used cars of higher expected quality. In the second class are consumers with relatively high valuation. These consumers are lessees, those with higher valuations choose contracts with higher option prices.

Because the environment facing a consumer is stationary, if a particular type of behavior is optimal for a consumer at date $t$ it will be optimal at all future dates where the consumer faces the same choice. Thus, if contract $i$ is best for a consumer of type $\theta$ at date $t$ it will be optimal at all future dates. 


\subsection{Equilibrium}

Equilibrium requires that supply equals demand in the used market and in the new market, and that expected quality $w_{i}^{u}$ equals the average traded quality $w_{i}^{A}$ for each type of car. As we explained in the introduction we still take as given the supply in the new market without specifying the market structure, we deal with optimal supplier's behavior later in the paper. The appendix states precisely how aggregate demand, supply and average traded quality are determined from individual behavior. ${ }^{15}$ It is easy to adapt the proof in Theorem 7 of Hendel and Lizzeri (1997b) to show that an equilibrium exists.

For the case in which all units are sold, Hendel and Lizzeri (1997b, Section 4.3) showed that the volume of trade in the used market is always strictly between zero and one hundred percent. When $P^{k}>P^{u}$, keeping a used car becomes less appealing, implying that the volume of trade will always be positive in this case as well. It is clear though that $P^{k}$ can be set so high as to discourage keeping altogether. Thus, under leasing we may have that the volume of trade is $100 \%$. We will show later that this is not optimal for a manufacturer. We now discuss some other features of equilibrium.

Proposition 5 Suppose that $P_{i}^{k}>P_{j}^{k}$. Then,

(i) If any consumer chooses contract $i, P_{i}^{L}<P_{j}^{L}$.

(ii) $w_{i}^{A}>w_{j}^{A}$, and $G\left(x_{i}(\theta)\right)>G\left(x_{j}\left(\theta^{\prime}\right)\right)>0 \forall \theta \in \Theta_{i}^{n}, \theta^{\prime} \in \Theta_{j}^{n}$; average quality and volume of trade are higher for the contract with the higher option price.

(iii) Contract i generates a higher present value of revenue per unit.

Proof: Part (i) is immediate; if $P_{j}^{L} \leq P_{i}^{L}$ no consumer would choose contract $i$.

Part (ii) is a consequence of Proposition 2 and Proposition 4. We want to show that, if $\theta$ buys contract $i$ and $\theta^{\prime}$ buys contract $j, x_{i}(\theta)>x_{j}\left(\theta^{\prime}\right)$. By Proposition $4, \theta>\theta^{\prime}$. Because $\theta$ chose contract $i, V_{i}^{L}(\theta) \geq V_{j}^{L}(\theta)$. Thus, from equation $6, x_{i}(\theta)>x_{j}(\theta)$. By proposition 2 , $x_{j}(\theta)>x_{j}\left(\theta^{\prime}\right)$. Thus, $x_{i}(\theta)>x_{j}\left(\theta^{\prime}\right)$.

\footnotetext{
${ }^{15}$ The determination of the equilibrium quantities is complicated by the need to account for the relative frequency with which different types of lessees keep their cars: as different types have different $x_{i}(\theta)$ s. For example, if a consumer of type $\theta$ always kept the car he would lease (and consume new) only half as often as a consumer of type $\theta^{\prime}$ who always returned his used car.
} 
To prove that $G\left(x_{j}\left(\theta^{\prime}\right)\right)>0 \forall \theta^{\prime} \in \Theta_{j}^{n}$, observe that the lowest $x_{j}\left(\theta^{\prime}\right)$ can be is in the case where $P_{j}^{k}=0$. But then contract $j$ is a selling contract and this is an immediate consequence of the positive volume of trade result in Hendel and Lizzeri (1997). This concludes the proof of (ii).

To prove part (iii), observe that the average discounted quality consumed by a consumer who chooses contract $i$ is strictly higher than the average quality consumed by a consumer who chooses contract $j$. If the present value of the expenditure by the consumer in contract $i$ was not also higher, nobody would choose contract $j$. Moreover, $P_{i}^{u}>P_{j}^{u}$ since the quality of used goods in contract $i$ is higher by part (ii). Thus, the present value of revenue per unit from contract $i$ is higher.

\subsubsection{Equilibrium Implications}

A special case of Proposition 5 is one where the only two options are a single selling contract and a single leasing contract. Thus, the results of Proposition 5 are consistent with the observed phenomena in the used car market discussed earlier. As we discussed in the introduction, there is a common perception in the automotive press and among consumers that the average quality of "off-lease" used cars is higher than the average quality of used cars that are sold by consumers who had bought their car. Moreover the average age of "off-lease" used cars is much smaller than the average age of non leased used cars that are sold in the used market for the first time. Thus, turnover is higher for leased cars. These phenomena are consistent with equilibrium behavior in our model by proposition 5 part (ii), for $P^{k}>$ $P^{u}$, the latter is the cost of keeping under a selling contract, which is perceived as lower than $P^{k}{ }^{16}$ In section 8.2 we solve for the optimal contract offered by a monopolist; we will see it indeed involves a much higher $P^{k}$ than $P^{u}$.

Observe that the menu of contracts serves to segment the market since different contracts appeal to different types. For the simple case where there are only two contracts, a leasing and a selling contract, part (i) says that the rental rate $P^{L}$ in the leasing contract is lower than the implicit rental rate in a selling contract. It may be puzzling that anybody would choose the selling contract if the rental rate is lower in the leasing contract. The reason some

\footnotetext{
${ }^{16}$ Guha an Waldman (1996) report that $P^{k}$ is on average $18 \%$ higher than $P^{u}$.
} 
types choose to buy is that in the selling contract the price of the option of keeping is lower. In a world with adverse selection, consumers value this option because they plan to keep the high realizations of quality of the used car. One can then ask the opposite question: if the option is so valuable, why does anybody choose the leasing contract with the high option price? The two questions together can be rephrased to ask why neither contract dominates the other from the point of view of consumers. The reason is that different types of consumers value the option differently. High valuation consumers do not value the option very much since they are not likely to keep the car, and therefore choose the leasing contract. Low valuation consumers, on the other hand, value the option more because they are more likely to keep the car. We shall come back in sections 7 and 8.2 to the issue of how the pricing of the keeping option influences equilibrium behavior and the profits of a manufacturer.

\section{Welfare}

We shall now discuss the welfare consequences of introducing leasing contracts. In this section we continue to ignore manufacturers' incentives to study what allocations can be achieved through leasing contracts and the limits of these contracts. It turns out that leasing contracts are powerful instruments when only two types of consumers are present. In the more general case, however, they do not achieve efficiency as shown by the following proposition.

Proposition 6 (i) If there are two types of consumers then the ex post efficient allocation can be obtained through a single leasing contract.

(ii) If there is more than one type of consumer buying used cars then the ex-post efficient allocation cannot be achieved through leasing contracts.

Proof: Part (i) is due to the fact that when there are only two types of consumers ex post efficiency is solely an issue of volume of trade. Let $\theta_{L}$ and $\theta_{H}$ be the two types, with $\theta_{L}<\theta_{H}$. Given $y$, the ex post efficient allocation requires that the high types consume the highest possible quality. Let $\mu$ be the measure of the set of high types. If $\mu \leq y$, the ex post efficient allocation involves high types never keeping. This can be achieved by setting a very high $P^{k}$. If $\mu>y$, let $x$ be the cut-off rule such that, if it is adopted by all high types, all 
high types consume new and no low type consumes new. ${ }^{17}$ It is easy to see that it is possible to find a $P^{k}$ that generates such keeping behavior by the high types as an optimal response. Thus, for any $y$ it is possible to construct contracts that generate ex post efficient allocations. It is then also possible to choose the efficient $y$.

To prove part (ii), denote by $\theta_{1}$ and $\theta_{2}$ two types of consumers such that $\theta_{1}<\theta_{2}$ and both are used car consumers. Let $w_{1}, w_{2}$ denote the qualities consumed by the two types. If these qualities are the result of equilibrium with leasing contracts, we have that $w_{1}=$ $E(w \mid$ contract 1$), w_{2}=E(w \mid$ contract 2$)$ for some contracts 1,2 (possibly identical). The form these expected qualities take is $E(w \mid$ contract $i)=E\left(w \mid w \leq x_{i}\right)$ for some $x_{i}$. Thus, there is an overlap in the support of the qualities consumed by the different types of consumers. This means that there is always a positive probability that low types of consumers end up consuming realizations of quality that are higher than the realizations of quality consumed by a consumer of type 2 . This is a violation of ex post efficiency.

Guha and Waldman (1997) suggest that leasing can lead to first best allocations. Throughout their analysis of the pure adverse selection case they assume that there are only two types of consumers. ${ }^{18}$ Part (i) of proposition 6 restates their result and generalizes it to any distribution of quality of used cars. ${ }^{19}$ Guha and Waldman also show that a competitive industry would provide the optimal leasing contract.

Part (ii) of Proposition 6 shows that the assumption of two types is crucial in their analysis; if there is more than one type consumer who buys used cars it is impossible to achieve ex post efficient allocations solely through leasing contracts. Leasing contracts make it possible to manipulate the volume of trade but it is not possible to solve the allocative distortion in the used market. Proposition 6 says that leasing contracts cannot achieve the ex post efficient allocation except in a very special case. This is because the leasing contracts cannot completely resolve the mismatching of qualities and types of consumers in the used market.

\footnotetext{
${ }^{17}$ See section 7 for an example that shows how this works.

${ }^{18}$ In their discussion of moral hazard they also discuss the case of an additional dimension of heterogeneity. Consumers can also differ by how costly it is for them to maintain the car.

${ }^{19}$ They assume that there are at most three types of used cars.
} 
Another important question is whether leasing contracts can achieve efficiency subject to incentive constraints. The following result shows that the answer to this question is negative. We show that it is possible to achieve the first best allocation even with an incentive compatible, individually rational and balanced budget mechanism. This implies that leasing contracts are incomplete tools.

Proposition 7 There exists an incentive compatible budget balanced mechanism that implements the first best allocation.

Proof: The first best allocation is described in proposition 1. The social planner can implement this through the following mechanism. Use a leasing contract with a very high $P^{k}$ so that nobody keeps and $P^{L}=\hat{P}^{L}$, from equation 3 . When a consumer returns the car he must report the quality of the car. Since his utility does not depend on his report it is (weakly) incentive compatible for him to tell the truth. The allocation in the used market can be decentralized with the function $P^{u}(w)$ described in equation 1 .

This replicates the first best allocation. Budget balance can easily be shown to hold for the optimal choice of output given a marginal cost $c$. This is because the revenues that are received by the social planner in the proposed mechanism are the same as the revenues in the world with observable quality.

Remarks: First note that this result is in stark contrast with what happens in static adverse selection models. The contrast is due to the fact that in our model, at the time the new car consumer enters into the contract, he does not yet know the quality of the car. Thus, his payment does not depend on this information. Since the ex post efficient allocation requires him to consume new goods every period, he should never keep the used good. Thus, extracting information about quality is not costly for the social planner.

Second, observe that there is a major difference between a leasing contract and the mechanism described in proposition 7. In a leasing contract there is no information communicated from the lessee to the used car consumers beyond that which is inferred from the equilibrium behavior. By proposition 6 the information transmitted via leasing contracts is much too coarse to lead to efficient allocations. 
The final result on welfare highlights the fact that $100 \%$ trade in the used market (i.e., if no consumer keeps used cars) is only optimal if quality can be allocated in the "right way" in the used market.

Proposition 8 If the social planner is constrained to using menus of leasing contracts, the allocation that maximizes consumer surplus does not involve full trade in the second hand market.

Proof: Suppose that the we start from an allocation with $100 \%$ trade. This implies that all types in $\left[\theta_{2 y}, \theta_{y}\right]$ consume used goods every date and all types in $\left[\theta_{y}, \theta^{h}\right]$ consume new goods every date. Take the set of consumers with types between $\theta_{y}$ and $\theta_{y}+\epsilon$. Instead of forcing them to trade, allow them to keep the high realizations of quality of the used (this can be implemented with a leasing contract with a slightly lower option price than the one that generates no keeping). The resulting equilibrium allocation will involve some consumers with slightly lower valuation consuming new cars (types in $\left[\theta_{y}-\zeta, \theta_{y}\right)$ ). We thus have a transfer of quality from types in $\left[\theta_{y}, \theta_{y}+\epsilon\right)$ to types in $\left[\theta_{y}-\zeta, \theta_{y}\right)$. This is bad from the welfare perspective. However, the quality of the used good falls because types in $\left[\theta_{y}-\zeta, \theta_{y}+\epsilon\right)$ keep some of the realizations of quality of the used good. Thus, there is also a transfer in quality from types in $\left[\theta_{2 y}, \theta_{y}-\zeta\right)$ to types in $\left[\theta_{y}-\zeta, \theta_{y}\right)$. This transfer is good for welfare. In other words, types in $\left[\theta_{y}-\zeta, \theta_{y}\right)$ gain at the expense of types in $\left[\theta_{y}, \theta_{y}+\epsilon\right)$ and $\left[\theta_{2 y}, \theta_{y}-\zeta\right)$. The welfare loss is negligible since types in $\left[\theta_{y}-\zeta, \theta_{y}\right)$ and types in $\left[\theta_{y}, \theta_{y}+\epsilon\right)$ are very close. The welfare gain however is substantial because types in $\left[\theta_{y}-\zeta, \theta_{y}\right)$ and those in $\left[\theta_{2 y}, \theta_{y}-\zeta\right)$ are not close on average. Thus this type of deviation from full trade is beneficial.

The logic of this result is the following. As we saw in proposition 6 , it is not possible to efficiently match the right used cars with the right types of consumers by only using leasing contracts. In this world, allowing some lessees to keep the high draws of the used good has good welfare consequences because it permits better matching of quality to types: it reduces the quality consumed by the lowest valuation consumers increasing the quality consumed by consumers with intermediate valuation. 


\section{Leasing and Market Power: Option Pricing and Optimal Output.}

We shall now discuss in detail a simple example where the optimal solution for a monopoly manufacturer is particularly easy to characterize. We discuss results and intuition in this section, while derivations are relegated to the Appendix. The point of the example is to show that the option of keeping the used good is mispriced in a selling contract. We explain the source of this mispricing and show how the optimal pricing of this option in a leasing contract allows the manufacturer to profitably expand output.

Consider two types of consumers, low valuation with $\theta_{L}=1 / 3$ and high valuation with $\theta_{H}=1$. There is a mass of $1 / 2$ of each type of consumer. We also assume that $\delta=.8, v=2$, and that $G(\cdot)$, the distribution of quality of used goods, is uniform on $[1-s, 1+s]$ with $s \in[0,1]$. The parameter $s$ represents the extent of asymmetric information; a low (high) $s$ means that there is little (a lot of) uncertainty about the quality of a used car. The role of the assumption $s \leq 1$ is to guarantee that $w_{h} \leq v$.

\subsection{Selling vs. Leasing}

We shall first fix output at $y=1 / 3$, solve for the equilibrium under selling, and then solve for the optimal leasing contract. Fixing a particular $y$ is a good starting point because the features of the solution will be very similar for all choices of $y$ but the discussion should be easier to follow for a particular numerical value of $y$. We will later obtain optimal output under both selling and leasing for the case of zero marginal cost. ${ }^{20}$

Selling: Since $y=1 / 3$, there are not enough new cars for the high types to consume new cars every period. Thus, in equilibrium some high types must consume some used cars. The equilibrium has the following features: (1) High types buy new cars and none of the low types buy new cars. (2) The keeping behavior of high types is $x\left(\theta_{H}\right)=1$, i.e. the high types keep the upper half of the realizations of quality of the used cars. The way we find the equilibrium (for details see Appendix B) is to solve the $P^{u}$ that clears the used market at

\footnotetext{
${ }^{20}$ An output of $1 / 3$ would be optimal for some weakly convex cost function. However, output under leasing would be different than under selling.
} 
the $w^{A}$ implied by $x\left(\theta_{H}\right)=1$, then solve the $P^{n}$ that makes $x\left(\theta_{H}\right)=1$ optimal, and finally show that the new market clears as well (since $x\left(\theta_{H}\right)=1$, high types keep half of their cars, hence the new market clears, as $\frac{1}{3}+\frac{1}{3} * \frac{1}{2}=\frac{1}{2}$, the latter is the mass of high types). Profits for the manufacturer in this case are: $\Pi^{S}=P^{n} y=.53333-s / 30$.

Leasing: In Appendix B we show that the manufacturer benefits from setting $P^{k}>P^{u}$ despite the fact that under the optimal leasing contract the equilibrium allocation is the same as under selling. The optimal contract here involves leasing only; because there are only two types, more complicated menus serve no purpose.

We saw that under selling market clearing requires that $x\left(\theta_{H}\right)=1$, implying that $P^{n}$ must be such that this keeping behavior is optimal for the high types. The important consequence of this is that under selling, $V^{n}\left(\theta_{H}\right)>V^{u}\left(\theta_{H}\right)$ (see $V^{n}$ and $V^{u}$ in Appendix B). This is in stark contrast with what happens when there is symmetric information in the used market. In the case of symmetric information the new car buyers must be indifferent between the new good and the best alternative, the highest quality used good. Under adverse selection, the new car buyers must be indifferent between buying a new car and keeping a used car of quality $x\left(\theta_{H}\right)$. This indifference is determined by the cost of keeping a used car of quality $x\left(\theta_{H}\right)$. Under selling, this cost is $P^{u}$ (the amount that would be received in the used market by selling the used car), but $P^{u}$ must equal $\theta_{L} w^{A}$ to clear the used market. This price is too low because it evaluates a lower quality good $\left(w^{A}<x\left(\theta_{H}\right)\right)$ by a lower valuation consumer $\left(\theta_{L}<\theta_{H}\right)$. This means that the option of keeping the used car is not fully priced for the high types. Thus, in a world with adverse selection, the competition for the new good is a used good that is priced too low. In contrast, in a world without information asymmetries the quality of the used good is observed in the market and therefore adequately priced. By raising the option price above the market clearing price in the used market $\left(P^{k}>P^{u}\right)$ the manufacturer can better price the keeping option and extract more rents from the high valuation consumers.

The equilibrium is solved in a similar way to the one described for selling, the only difference is that the manufacturer has two instruments to make $x\left(\theta_{H}\right)=1$, they are $P^{k}$ and $P^{L}$. Actually, there are many pairs of $\left(P^{L}, P^{k}\right)$ that generate $x\left(\theta_{H}\right)=1$ as optimal keeping behavior. The following expression describes the market clearing $P^{L}$ that corresponds to any 
given $P^{k}$ :

$$
L\left(P^{k}\right)=1+.2 s+P^{k}
$$

Expression 9 is remarkable; as the manufacturer increases $P^{k}$, one would expect that the rental price of the new good would have to fall to compensate for the fact that the option becomes less attractive as $P^{k}$ increases. However, this reasoning does not take into account the fact that markets must clear. If a fall in $P^{L}$ were to coincide with an increase in $P^{k}$, keeping a used car of any given quality would become less attractive relative to starting a new lease. We would then have excess demand for new cars. ${ }^{21} P^{k}$ will be set to equalize $V^{L}\left(\theta_{H}\right)$ and $V^{u}\left(\theta_{H}\right)$, yielding $P^{k}=1 / 3+s / 3$ and $P^{L}=4 / 3+.5333 s$. Profits for the manufacturer under this optimal leasing contract are $\Pi^{L}=.5333+.2 s$. By comparing with profits under selling we see that $\Pi^{L}-\Pi^{S}=s / 6$, which is positive for any nondegenerate distribution of quality of the used good.

In contrast with what we saw under selling, profits under the optimal leasing contract are increasing in $s$. In both cases the increase in $s$ lowers $P^{u}$ and increases the expected value of the cars kept by the high types. In the case of selling, the reduction in the used price makes keeping more appealing relative to buying, while in the case of leasing the cost of keeping is $P^{k}$, not $P^{u}$; leasing allows the manufacturer to control the pricing of the option, reducing the competitive threat that the used good poses to the new good.

It is interesting to consider endogenizing $s$ (the design of the car). One can see that the manufacturer would have an incentive to design cars with high $s$ under leasing and low $s$ under selling. Observe that social surplus is increasing in $s$ since the average quality consumed by high types increases and the average quality consumed by low types falls. This generates a better fit between types of consumers and qualities of cars. Thus, under leasing the design of the car is going to be better from a social welfare perspective.

\subsection{The Choice of Optimal Output}

So far we have restricted attention to the case where $y=1 / 3$. We now derive the optimal output for different values of $s$ under the assumption of zero marginal cost. In Appendix B

\footnotetext{
${ }^{21}$ This phenomenon is not always present in a world with a continuum of types.
} 
we show that the optimal output under leasing is $y=.5$ for all values of $s$ while optimal output under selling depends on $s$; for low values of $s$ optimal output is $y=.5$, for high values of $s$ optimal output is $y=.25$. Thus, a monopolist who leases may produce more output than one who sells.

Selling: In the appendix we show that for $s \leq .2$ optimal output is .5. For $s>.2$ optimal output is .25. At $s=.2$ the manufacturer is indifferent between the two values. Finally, we compute $\Pi^{S}(y, s)=P^{n} y$. For $s \leq .2$ profits are increasing in $y$ until .5. Thus $y=.5$ is optimal for $s \leq .2 . \Pi^{S}(.5, s)=.8-.5 s$. Since $\Pi^{S}(.25, s)=.7, y=.25$ is optimal for $s>.2$.

Let us first discuss the intuition for the fact that low output is optimal for high values of $s$ whereas high output is optimal for low values of $s$. When $y=.25$, high types keep all the draws of quality of the used good and no low type buys the used good. The expected utility from keeping the used good for all realizations of quality is independent of $s$ because the average quality is 1 for all $s$. Since in this case the condition that sets $P^{n}$ is that the high types must have zero utility, $P^{n}$ is independent of $s$. When $y=.5$, none of the high types keep any of the draws of the used good. For this to be optimal, from equation 6 , we must have that

$$
\theta_{H} x\left(\theta_{H}\right)-P^{u}=(1-\delta) V^{n}\left(\theta_{H}\right)
$$

Since market clearing requires that high types never keep, $P^{u}$ is constant in $s\left(P^{u}=\theta_{L} E(w)\right)$. However, $x\left(\theta_{H}\right)=1+s$ is increasing in $s$. Thus, the left hand side of equation 10 increases with $s$; as $s$ increases, the higher types must be indifferent between buying a new car and keeping a higher quality used car. Since the high type never keeps the used good, $(1-\delta) V^{n}\left(\theta_{H}\right)=$ $\theta_{H}-P^{n}+\delta P^{u}$. Thus, for the right hand side of equation 10 to also increase with $s$, the price of the new good must drop. The competition from high quality used cars explains why $\Pi^{s}(1 / 2, s)$ declines in $s$, hence maximized at $s=0$. To conclude, since $P^{n}$ is independent of $s$ for $y=.25$ but is declining in $s$ for higher $y$ 's, then for low $s$ a high output is optimal and for high $s$ a low output is optimal.

Observe that at $y=.5$ the option of keeping is not used in equilibrium by the high types because they never keep. However, the presence of this option still affects equilibrium prices and profits because market clearing prices must be such as to make the high types prefer not to keep even the highest draws of the used good. We will see that this implies that leasing 
has an effect even in a world where the option is not utilized.

Leasing: As in the case of $y=1 / 3$, by choosing $P^{k}$ the manufacturer gets to price the option of keeping high quality draws of the used good. This allows the manufacturer to extract more from the high types and makes keeping less appealing, hence less of a threat to the sale of new units. As shown in Appendix B, for $s>0, y>.25$, in the equilibrium under selling, $V^{n}\left(\theta_{H}\right)>V^{u}\left(\theta_{H}\right)$; high types strictly prefer new cars to used cars. This means that by increasing $P^{k}$ the manufacturer can reduce $V^{n}\left(\theta_{H}\right)$ without changing the equilibrium allocation, thereby extracting more surplus from the high types. This is because, by pricing the option, the manufacturer effectively eliminates the problems associated with high $s$ under selling. That is, the manufacturer does not have to lower the price of the new good to avoid excessive keeping by the high types. This implies that under leasing optimal output will be $y=0.5$ independent of $s$, hence higher than under selling. Profits are $\Pi^{L}\left(0.5, s, P^{k^{*}}\right)=0.8$, which is independent of $s$. These are the maximum attainable profits and under selling were only achieved at $s=0$.

An interesting observation that may lead to empirical predictions is the fact that the manufacturer benefits more from leasing if $s$ is high. Thus, we would expect manufacturers with unreliable brands to lease more.

The presence of asymmetric information is crucial for all of the previous analysis. Indeed, we showed in section 4, in a world with no information asymmetries, leasing has no effects on the equilibrium allocation and on profits. This is because in such a world the value of the option of keeping is priced in the used market according to the actual quality of the used good.

Remark: In the example that we have discussed, the profits from leasing come from the fact that under selling the utility that the high types receive from buying a new car is strictly higher than the utility they would get from buying a used car. In a world with a continuum of types there must always be a type who is indifferent between buying used and buying new. Does this mean that our example has nothing to say about a world with a continuum of types? The answer is no. In this world there are additional effects which influence the optimal pricing of the option in a leasing contract. However, something similar to what we uncovered in our two type example still exists. The type who is indifferent (the marginal type) depends 
on $P^{k}$. To see this, observe first that we could write down a continuous approximation of the two type example and the optimal solution would be very similar. Thus, the fact that the marginal type is indifferent between new and used in the continuous case does not affect the logic of our example. In a more general case the option of keeping may still be priced too low to induce the desired keeping behavior by lessees. It will no longer be possible to increase $P^{k}$ and leave unchanged the equilibrium allocation because some types would stop leasing and become used car buyers. However, this effect would be beneficial to the manufacturer because the marginal lessee would be higher.

\section{Optimal Menus of Contracts}

\subsection{Is Full Trade Optimal for Manufacturers?}

It is puzzling that most leasing contracts include the option of keeping the car at all. After all, the very expression "adverse selection problem" suggests that leasing contracts with a prohibitive option price would benefit manufacturers because they allow a "solution" of this problem. A leasing contract with a very high option price would make it optimal for consumers to never exercise their option of keeping and would get rid of adverse selection in the used market. Any $P^{k} \geq \theta_{y}\left(w_{h}-E(w)\right)+\theta_{2 y} E(w)$ would be such that no lessee would ever want to exercise the option.

The following result shows that this reasoning is flawed. It does not take into account the benefits of market segmentation. Here we go back to assuming that the distribution of consumer tastes $F(\cdot)$ is continuous and increasing.

Proposition 9 It is never optimal for a monopolist to offer contracts that make all consumers return their cars at the expiration of the lease.

Proof: Fix $y$. Let $P^{k}, P^{u}, P^{L}$ be the equilibrium values that generate $100 \%$ trade. The lowest $P^{k}$ that works is $P^{k}=\theta_{y}\left(w_{h}-E(w)\right)+\theta_{2 y} E(w)$. Note that $P^{u}=\theta_{2 y} E(w)$ since the lowest type who buys used must be indifferent between buying used and buying nothing. The monopolist can change the contract in the following way. Keep the same $y$, offer one contract with $P_{1}^{k}=P^{k}, P_{1}^{L}=P^{L}$, and offer a second contract with $P_{2}^{k}$ slightly smaller than 
$P_{1}^{k}$. Observe that $P_{2}^{L}$ is free to vary so that the market clears (recall that $P_{1}^{L}$ is fixed). At the lower $P_{2}^{k}$ some people who lease will want to keep the used good. Thus in the second hand market we have two types of cars: ones coming out of contract 1 and ones coming out of contract 2. The first set of cars has quality $E(w)$. The second set of cars has quality $w_{2}^{A}$ which is slightly smaller than $E(w)$. By proposition 4 lowest types will buy the low quality used car. The price will be $P_{2}^{u}=\theta_{2 y} w_{2}^{A}$. The price of the better used car is now determined by making the lowest type who buys this car (let's call him $\theta_{1}$ ) indifferent between this car 1 and the lower quality one. Thus, $\theta_{1} E(w)-P_{1}^{u}=\theta_{1} w_{2}^{A}-P_{2}^{u}=\left(\theta_{1}-\theta_{2 y}\right) w_{2}^{A}$. Thus $P_{1}^{u}=\theta_{1}\left(E(w)-w_{2}^{A}\right)+\theta_{2 y} w_{2}^{A}$. Therefore, $P_{1}^{u}-P_{2}^{u}=\left(\theta_{1}-\theta_{2 y}\right)\left(E(w)-w_{2}^{A}\right)>0$. We thus have the first effect on profits: the used cars of type 1 are sold at a higher price under the new menu of contracts.

By proposition 5 a second effect is also positive: $P_{2}^{L} \geq P_{1}^{L}$ since $P_{1}^{k}>P_{2}^{k}$.

Thus, to prove that introducing the second leasing contract is profitable, it is sufficient to prove that the used cars of type 2 are also sold at a higher average price than $\theta_{2 y} E(w)$ (i.e. $P^{u}$ ). The used units that are kept by the lessees are sold by the monopolist at a price of $P_{2}^{k}$. This price can be made arbitrarily close to $P^{k}=\theta_{y}\left(w_{h}-E(w)\right)+\theta_{2 y} E(w)$, which is the lowest $P^{k}$ that generates no keeping. The units that are returned are sold at $P_{2}^{u}=\theta_{2 y} w^{A}$. Let $w^{k}$ be the average quality of kept units and let $\theta_{2}$ be the lowest type who leases contract 2. All the units that are kept are not sold in the used market. Therefore $E(w)$ is an average of $w^{A}$ and $w^{k}: E(w)=\alpha w^{k}+(1-\alpha) w^{A}$. The average price at which the used units are sold is $E(P)=\alpha P_{2}^{k}+(1-\alpha) \theta_{2 y} w^{A}$. As mentioned above, $P_{2}^{k}$ can be made arbitrarily close to $P^{k}=\theta_{y}\left(w_{h}-E(w)\right)+\theta_{2 y} E(w)$. Thus, $E(P)$ is approximately $\alpha \theta_{2}\left(w^{k}-w^{A}\right)+(1-\alpha) \theta_{2 y} w^{A}$. But the old $P^{u}$ can be rewritten as $P^{u}=\alpha \theta_{2 y} w^{k}+(1-\alpha) \theta_{2 y} w^{A}$. Subtracting the RHS of the second equation from the RHS of the first, we get: $\alpha\left[\left(\theta_{2}-\theta_{2 y}\right) w^{k}-\left(\theta_{2}-\theta_{2 y}\right) w^{A}\right]>0$ since $w^{k}>E(w)$ and $\theta_{2}>\theta_{2 y}$. This concludes the proof.

The phenomenon presented in proposition 9 is due to the following force. As we saw in proposition 8 , social welfare is increased by not restricting the allocation to $100 \%$ trade. The monopolist gets to capture some of this increase in surplus through a segmentation of the market. As $P^{k}$ is reduced on one contract, some of the high quality used units are consumed by high types. While this reduces the price in the used market, this reduction is more than 
compensated for by the fact that the option price of these units is much larger.

The logic of the proof of proposition 9 does not depend on the assumption of a monopoly manufacturer. In fact, a subset of the proof is sufficient to show that $100 \%$ trade would never be an equilibrium outcome in a world where there is perfect competition among firms that offer leasing contracts. A firm that deviates and offers the contract described in the proof would increase its profits. In fact, the proof would be easier because in such a case we would not need to worry about the old contract remaining profitable.

Guha and Waldman provide an example where the equilibrium outcome in a competitive industry involves allowing the option of keeping. The difference is that we show that for any continuous increasing distribution equilibrium outcomes must always include this option.

\subsection{Uniform Preferences: An Example with a Continuum of Valuations}

In this section we provide an example where preferences are uniformly distributed. The purpose of this section is to show the functioning of the model and the gains from leasing in an example with a continuous distribution of consumer valuations and to determine quantitatively the effects from optimally mixing selling and leasing.

Assuming $G$ is uniform is convenient since it leads to an analytic solution for $x(\theta)$. By

plugging the uniform distribution of quality in the expressions that define $V^{L}$ and $x(\cdot)$ in Proposition 2 we get:

$$
x(\theta)=1+\frac{P^{k}}{\theta}+s+\frac{2 s}{\delta}-\frac{1}{\delta \theta} \sqrt{4 \theta s\left(\delta \theta+\delta P^{k}+(1+\delta) \theta s-\delta \theta v+\delta P^{L}\right)+\left(\delta P^{k}\right)^{2}}
$$

The model could be solved for any distribution function, but the solution would involve numerically approximating $x(\theta)$ in a grid of values of $\theta$. The enormous computational simplicity gained by using the uniform distribution is clear; it avoids having to nest one fixed point into another (nesting the one that generates $x(\theta)$ into the one that determines the equilibrium prices and quantities).

We computed the equilibrium by finding optimal behavior of each consumer for every set of prices and expected used quality. Then we aggregated behavior to define market demand and supply just as in the appendix. Finally we searched for the prices and quality that clear markets. We found equilibrium quantities by minimizing a norm of the excess demand function. The search was done using Matlab; codes are available upon request. 
We assume that the support of the distribution of $\theta$ is $[0,1]$, while the support of the distribution of $w$ is $[0.5,1.5]$. We computed the equilibrium for $v=2, \delta=0.8, s=.5$ and different output levels $y$ and $P^{k}$. We then checked which output and keeping price maximizes profits for the lessor and compared to profits from selling. When selling the optimal output is $y=0.306$, which leads to $P^{u}=0.31, P^{n}=1.35, \operatorname{VOT}$ (volume of trade) $=56 \%$, and profits are 0.4105 . When leasing the manufacturer produces almost the same output level, $y=0.303$, but sets a $P^{k}=0.655$ which leads to $P^{u}=0.385, P^{L}=1.082$, VOT $=97 \%$, and profits of .426 .

Thus it pays for the manufacturer to set the option price above the market clearing price in the used market but below the price that would generate full trade. It is not in the manufacturer's interest to completely "solve" the adverse selection problem.

When the manufacturer leases and sells at the same time, the optimal solution is the following. The optimal values for prices are: $P^{L}=1.0828, P^{k}=0.6550$, and $P^{n}=1.4096$. At these prices the manufacturer leases 0.285 units with and sells 0.02 units. The volume of trade of the leased units in the second hand market is almost 100\% (97\%); lessees keep only $3 \%$ of the cars. In contrast, the volume of trade of the sold units is $31 \%$, less than a third of the volume of trade of the leased units. The average quality of the leased units is $30 \%$ higher than the average quality of the sold units. The prices in the used market are $P_{1}^{u}=0.2569$, $P_{2}^{u}=0.3878$. Thus, prices of off-lease cars are more than $50 \%$ higher.

These numbers are interesting because they suggest that quantitatively important differences in the behavior of lessees and buyers can arise as the outcome of market segmentation by manufacturers with market power and optimal behavior by consumers in a world with adverse selection. This gives us some hope that the phenomena described in the introduction can be attributed at least to some extent to the forces discussed in this paper.

\section{Appendix}

\subsection{Aggregate Quantities}

Let $\theta_{i}^{1}=\inf \left\{\theta \in \Theta_{i}^{n}\right\}$ and $\theta_{i}^{2}=\sup \left\{\theta \in \Theta_{i}^{n}\right\}$

The determination of $w_{i}^{A}$ is complicated by the need to account for the relative frequency 
with which different types of consumers are in the market: different consumers have different trading behavior so they show up with different frequencies on the market. For example, if a consumer of type $\theta \geq \theta^{n}$ always kept its used car he would show up on the new market only half as often as a consumer of type $\theta^{\prime}$ who always sold his used car.

Proposition 10 The quality traded in the used market is:

$$
w_{i}^{A}=\int_{\theta_{i}^{1}}^{\theta_{i}^{2}} E\left(w \mid w \leq x_{i}(\theta)\right) d H_{i}(\theta)
$$

Where

$$
H_{i}(\theta)=\frac{\int_{\theta_{i}^{1}} \theta \frac{G\left(x_{i}(s)\right)}{\left[2-G\left(x_{i}(s)\right)\right]} d F(s)}{\int_{\theta_{i}^{1}}^{\theta_{i}^{2}} \frac{G\left(x_{i}(s)\right)}{\left[2-G\left(x_{i}(s)\right)\right]} d F(s)}
$$

denotes the distribution of consumer types who trade in the used car market at any given date.

Proof: The expression for $w_{i}^{A}$ has a simple explanation: the average quality returned by a type $\theta$ consumer is $E\left(w \mid w \leq x_{i}(\theta)\right)$. By integrating over all $\theta \in \Theta_{i}^{n}$ we obtain the average quality of cars of type $i$ that are offered in the used market. The only thing that needs to be explained is the expression for $H_{i}(\theta)$ that is the distribution with respect to which we are integrating.

Denote by $\operatorname{pr}_{t}(\theta)$ the proportion of consumers of type $\theta$ who lease at date $t$. Observe that $\left(1-G\left(x_{i}(\theta)\right)\right) \operatorname{pr}_{t}(\theta)$ will decide to keep the car as their quality realization is higher than $x(\theta)$. We can solve for $\operatorname{pr}(\theta)$ by using the fact that, in a steady state, $1-\operatorname{pr}_{t}(\theta)=$ $\left(1-G\left(x_{i}(\theta)\right)\right) p r_{t-1}(\theta)$, that is, the proportion of lessees of type $\theta$ who do not lease on any given date should equal the proportion of those getting high quality realizations out of the lessees in the previous period. Thus we get:

$$
p r_{i}(\theta)=\frac{1}{\left(2-G\left(x_{i}(\theta)\right)\right.}
$$

This explains the numerator of $H_{i}(\theta)$. The denominator is simply to normalize so that $H_{i}(\cdot)$ is a probability distribution. 
Proposition 11 Supply of used cars of type $i$ is:

$$
y_{i s}^{u}=\int_{\theta_{i}^{1}}^{\theta_{i}^{2}} \frac{G\left(x_{i}(\theta)\right)}{\left[2-G\left(x_{i}(\theta)\right)\right]} d F(\theta)
$$

Demand for used cars of type $i$ is:

$$
y_{i d}^{u}=\mu\left(\Theta_{i}^{u}\right)
$$

Demand in the market for new cars is:

$$
y_{i d}^{n}=\int_{\theta_{i}^{1}}^{\theta_{i}^{2}} \frac{1}{\left[2-G\left(x_{i}(\theta)\right)\right]} d F(\theta)
$$

\subsection{Proof of Proposition 4.}

Proof: Part (i) is an immediate consequence of lemma 3.

Let us now prove part (ii). Assume that there are only two contracts, 1 and 2 with $P_{1}^{k}<P_{2}^{k}$. Suppose by way of contradiction that $\theta \in \Theta_{2}^{n}, \theta^{\prime} \in \Theta_{1}^{n}$, and $\theta<\theta^{\prime}$. Note first that $\Theta_{i}^{n}=\left\{\theta: V_{i}^{L}(\theta)>V_{j}^{L}(\theta), i \neq j, V_{i}^{L}(\theta)>V_{h}^{u}(\theta)>0, \forall i, h\right\}$. Because the $V$ functions are continuous, $V_{2}^{L}(\theta)-V_{1}^{L}(\theta)$ is continuous. Therefore, it must be the case that for any $\epsilon$, there exist $\alpha, \beta$ such that $\alpha \in \Theta_{2}^{n}, \beta \in \Theta_{1}^{n}$, and $\beta-\alpha<\epsilon$, with $\epsilon>0$. By the continuity of $x_{i}(\theta)$, for $\alpha$ and $\beta$ very close, $x_{1}(\alpha) \simeq x_{1}(\beta)$ and $x_{2}(\alpha) \simeq x_{2}(\beta)$. We can then conclude that, because $P_{2}^{k}>P_{1}^{k}$, by equation $6, x_{2}(\alpha)>x_{1}(\beta)$. Since contract 2 is the contract chosen by type $\alpha$ and contract 1 is the contract chosen by type $\beta$, this implies that the actual cut-off rule given the optimal choice of contract involves type $\alpha$ keeping fewer realizations of the used good. But the average discounted quality consumed by a lessee who uses a cut-off rule $x$ is

$$
q(x)=\frac{v+\delta(1-G(x)) E(w \mid w \geq x)}{1-\delta G(x)-\delta^{2}(1-G(x))}
$$

which is increasing in $x$. Since $\beta>\alpha$, an application of lemma 3 to types $\alpha$ and $\beta$, and qualities $q\left(x_{1}(\alpha)\right)$ and $q\left(x_{2}(\beta)\right)$ yields the desired contradiction.

When the number of contracts is bigger than 2 there is always a pair of contracts such that we can replicate the above exercise.

Part (iii) is again a consequence of lemma 3 plus the fact that the average discounted quality consumed by a lessee is higher than the average discounted quality consumed by a 
used car buyer for any $i, j$. To see this, observe that, because $v \geq w_{h}, q(x)>w_{i}^{u} /(1-\delta)$, where $q(x)$ is defined in equation 15 .

\section{Appendix B}

\section{$10.1 \quad$ Fixed Output}

Selling: We first prove the optimality of consumer behavior and derive equilibrium prices. Given that the high types are the only sellers of used cars, the average quality of used cars is $w^{A}=E\left(w \mid w \leq x\left(\theta_{H}\right)\right)=\left(1-s+x\left(\theta_{H}\right)\right) / 2=(2-s) / 2$. The market clearing price of used cars is $P^{u}=\theta_{L} w^{A}=(2-s) / 6$. At this price $V^{u}\left(\theta_{L}\right)=0$; the low types are indifferent between buying used cars and buying nothing. The equilibrium $P^{n}$ must be such that $x\left(\theta_{H}\right)=1$, the postulated keeping behavior for the high types. By combining equations 6 and 8 , given that $P^{u}=(2-s) / 6$, we obtain $P^{n}=1.6-.1 s$. Given $P^{n}$ and $P^{u}$, we have $V^{n}\left(\theta_{H}\right)=10 / 3+5 s / 6>V^{u}\left(\theta_{H}\right)=10 / 3-5 s / 3>0$. This shows that it is optimal for the high types to be new car buyers. Finally, $V^{n}\left(\theta_{L}\right)<0$. This guarantees that low types do not want to buy new cars and confirms that the postulated behavior is optimal.

It is easy to see that both markets clear. First, the new market clearing condition: $y\left(1+\left(1-G\left(x\left(\theta_{H}\right)\right)\right)=\frac{1}{2}\right.$ (where $\frac{1}{2}$ is the mass of high types) holds at $\left.x\left(\theta_{H}\right)\right)=1$. Whereas at market clearing prices low types are indifferent between buying and not buying a used car. Thus, we can pick a mass of $1 / 6$ of low types to be used car demanders to clear the used market.

Leasing: In order to obtain the optimal leasing contract, let us conjecture that the allocation in the market is the same as under selling. This implies that $x\left(\theta_{H}\right)=1$. Because of this, $P^{u}=(2-s) / 6$, just as under selling. To obtain $x\left(\theta_{H}\right)=1$ as optimal behavior, from equation 6 we must have $1-P^{k}=(1-\delta) V^{L}\left(\theta_{H}\right)$. Let $L\left(P^{k}\right)$ be a function that specifies $P^{L}$ such that the last equation is satisfied. By substituting from equation 7 , we get equation 9 :

Because $x\left(\theta_{H}\right)$ is constant by construction, and $L\left(P^{k}\right)$ (equation 9 ) is increasing in $P^{k}$, profits are increasing in $P^{k}$. Thus the manufacturer will want to increase $P^{k}$ as high as possible. However, $P^{k}$ cannot be increased indefinitely since $V^{L}\left(\theta_{H}\right)$ is decreasing in $P^{k}$ 
whereas $V^{u}\left(\theta_{H}\right)$ is independent of $P^{k}$. Therefore, if $P^{k}$ is set too high, we would have $V^{L}\left(\theta_{H}\right)<V^{u}\left(\theta_{H}\right)$ and the high type would buy a used car. But then the market would not clear. We can conclude that $P^{k}$ will be set to equalize $V^{L}\left(\theta_{H}\right)$ and $V^{u}\left(\theta_{H}\right) .{ }^{22}$ The equation $V^{L}\left(\theta_{H}\right)=V^{u}\left(\theta_{H}\right)$, yields $P^{k}=1 / 3+s / 3$ and, from equation $9, P^{L}=4 / 3+.5333 s$. Since $V^{L}\left(\theta_{H}\right)=V^{u}\left(\theta_{H}\right)$, and $V^{u}\left(\theta_{L}\right)=0 \geq V^{L}\left(\theta_{L}\right)$, it is optimal for both types of consumers to behave as postulated. This proves that the proposed allocation is part of an equilibrium.

\subsection{Optimal Output}

Selling: We shall discuss how we obtain optimal output for every $s \leq .7$. The answer is the same for $s \in[.7,1]$ but the analysis is more complicated. ${ }^{23}$ We now show that for $s \leq .2$ optimal output is .5. For $s>.2$ optimal output is .25 . At $s=.2$ the manufacturer is indifferent between the two values. It is clear that $y<.25$ cannot be optimal. If $y \leq .25$ high types buy new and keep all draws, and low types buy nothing at all. Thus, $P^{n}=$ $\theta_{H}(v+\delta E(w))=2.8$. Since $P^{n}$ is independent of $y$ in this range, $\Pi^{S}(y, s)=y P^{n}$ is increasing in $y$ up to $y=.25$, and $\Pi^{S}(0.25, s)=0.7$. It is also easy to show that $y>.5$ cannot be optimal since in that case the marginal type who determines the price of new cars becomes $\theta_{L}$.

For all $y \in[.25, .5], s \leq .7$, the equilibrium allocation has the same features as the one derived for the case of $y=1 / 3$; all high types buy new cars and none of the low types buy new cars. Thus the keeping behavior of high types, $x\left(\theta_{H}\right)$, must be such that the market for new cars clears, i.e., output plus the mass of used units that are kept should equal $1 / 2$, the mass of high types. Thus $y\left(1+\left(1-G\left(x\left(\theta_{H}\right)\right)\right)=\frac{1}{2}\right.$. Since $G\left(x\left(\theta_{H}\right)\right)=\frac{x\left(\theta_{H}\right)-1+s}{2 s}$ we get $x\left(\theta_{H}\right)=1+3 s-\frac{s}{y}$. Just as in the case of $y=1 / 3$, given $x\left(\theta_{H}\right)$ we get $w^{A}=E\left(w \mid w \leq x\left(\theta_{H}\right)\right)=$ $\left(x\left(\theta_{H}\right)+1-s\right) / 2=1+s-s / 2 y$ and $P^{u}=\theta_{L} w^{A}=\frac{1+s-s / 2 y}{3}$. The equilibrium $P^{n}$ must be such as to make $x\left(\theta_{H}\right)$ satisfy equation 6 . Plugging $P^{u}$ and $x\left(\theta_{H}\right)$ in equation 6 we get the

\footnotetext{
${ }^{22}$ Both here and in the following analysis we do not discuss the case where $P^{k}$ is set so high that some high types buy used goods. This is just to avoid making the discussion of the example excessively long. However, it is easy to see that such a policy cannot be optimal for the monopolist.

${ }^{23}$ When $s$ is very high and $y$ is close to .5 , the equilibrium allocation must involve some low types buying new. This creates some complications in the calculation of the equilibrium $w^{A}$. However, in that range of $s$ the optimal solution is still $y=.25$.
} 
$P^{n}$ that makes the high types indifferent between keeping $x\left(\theta_{H}\right)$ and buying new again. It is easy to verify that these variables define an equilibrium because $V^{n}\left(\theta_{H}\right) \geq V^{u}\left(\theta_{H}\right)$, and $V^{n}\left(\theta_{L}\right) \leq V^{u}\left(\theta_{L}\right)=0$.

Leasing: To clear the market we use the same $x\left(\theta_{H}\right)\left(x\left(\theta_{H}\right)=1+3 s-\frac{s}{y}\right)$ as under selling. This determines the same $P^{u} . P^{L}$ is found by plugging $x\left(\theta_{H}\right)$ and $P^{k}\left(\right.$ instead of $\left.P^{u}\right)$ in equation 6. As in the previous analysis, profits increase in $P^{k}$, which is then set as high as possible so that $V^{L}\left(\theta_{H}\right)=V^{u}\left(\theta_{H}\right)$. This maximizes the surplus extraction from the high types. After plugging the optimal $P^{k}$ we find that $\Pi^{L}\left(y, s, P^{k^{*}}\right)=1.45 y-1.35 y s+.675 s$. Profits are maximized, in the relevant range, at $y=0.5$. In contrast to the optimal output under selling, even for a large $s$ the manufacturer sells $y=0.5$.

\section{References}

Akerlof, G. (1970). "The Market for Lemons: Qualitative Uncertainty and the Market Mechanism" Quarterly Journal of Economics, August, 488-600.

Bond, E. and W. Samuelson (1987). "The Coase Conjecture does not hold for Durable Good Monopolies with Depreciation." Economics Letters , 24: 93-97.

Bulow, Jeremy. (1986) "An Economic Theory of Planned Obsolescence." Quarterly Journal of Economics, 101: 729-749.

Desai, P and D. Purohit (1998). "Leasing and Selling: Optimal Marketing Strategies for a Durable Good Firm", forthcoming Management Science.

Guha, R., Waldman, M. (1996) "Leasing Solves the Lemons Problem". Mimeo Cornell University.

Grenadier, S. (1995). "Valuing Lease Contracts A Real-Options Approach," Journal of Financial Economics, 38, 297-331.

Grenadier, S. (1996). "Leasing and Credit Risk," Journal of Financial Economics, 42, 333-3654.

Hendel, I and Lizzeri, A. (1997a) "Interfering with Secondary Markets", Mimeo 
Hendel, I. and Lizzeri, A. (1997b) "Adverse Selection in Durable Goods Markets", NBER Working Paper No 6194.

Laffont, J.J. and Tirole, J. (1996) "Pollution Permits and Compliance Strategies," Journal of Public Economics, 62, 85-125.

McConnell, J and J. Schallheim (1983) "Valuation of Asset Leasing Contracts," Journal of Financial Economics,12, 237-261.

Mussa, M. and S. Rosen. (1978). "Monopoly and Product Quality," Journal of Economic Theory, 18: 301-317.

Sattler, P. (1995). "New Cars, Used Cars and Clunkers: The imperfect Substitutability of Used Goods and Patterns of Trade in the Market for Durables: Theory and Evidence", mimeo Northwestern University.

Sharpe, S. and H. Nguyen (1995) "Capital Market Imperfections and the Incentives to Lease," Journal of Finance, 39 271-294.

Smith, C. and L Wakeham (1985). "Determinants of Corporate Leasing Policy," Journal of Finance, 15, 895-910.

Waldman, M. (1996b). "Eliminating the Market for Secondhand Goods: An Alternative Explanation for Leasing", Journal of Law and Economics, XL: 61-92. 